\title{
$\alpha$-Herpesvirus glycoprotein D interaction with sensory neurons triggers formation of varicosities that serve as virus exit sites
}

\author{
Nick De Regge, ${ }^{1}$ Hans J. Nauwynck, ${ }^{1}$ Kristin Geenen, ${ }^{1}$ Claude Krummenacher, ${ }^{3}$ Gary H. Cohen, ${ }^{3}$ \\ Roselyn J. Eisenberg, ${ }^{4}$ Thomas C. Mettenleiter, ${ }^{5}$ and Herman W. Favoreel ${ }^{1,2}$ \\ 'Laboratory of Virology and 'Laboratory of Immunology, Faculty of Veterinary Medicine, Ghent University, 9820 Merelbeke, Belgium \\ ${ }^{3}$ Department of Microbiology, School of Dental Medicine, and ${ }^{4}$ Department of Pathobiology, School of Veterinary Medicine, University of Pennsylvania, \\ Philadelphia, PA 19104 \\ ${ }^{5}$ Friedrich-Loeffler-Institut, Federal Research Institute for Animal Health, Institute of Molecular Biology, D-17493 Greifswald-Insel Riems, Germany
}

$\alpha$ -Herpesviruses constitute closely related neurotropic viruses, including herpes simplex virus in man and pseudorabies virus (PRV) in pigs. Peripheral sensory neurons, such as trigeminal ganglion (TG) neurons, are predominant target cells for virus spread and lifelong latent infections. We report that in vitro infection of swine TG neurons with the homologous swine $\alpha$-herpesvirus PRV results in the appearance of numerous synaptophysinpositive synaptic boutons (varicosities) along the axons. Nonneuronal cells that were juxtaposed to these varicosities became preferentially infected with PRV, suggesting

\section{Introduction}

$\alpha$-Herpesviruses are a subfamily of the herpesviruses containing closely related human and animal pathogens, including human herpes simplex virus 1 (HSV-1; cold sores, corneal blindness, and encephalitis) and important animal viruses such as the porcine pseudorabies virus (PRV) and bovine herpesvirus 1 (BoHV-1; respiratory symptoms, abortions, and/or neurological symptoms). Many of the disease symptoms observed after infection with $\alpha$-herpesviruses are associated with their neurotropic behavior, including their ability to establish lifelong cycles of latency and reactivation in the peripheral nervous system of their host (Preston, 2000; Enquist et al., 2002). Primary replication of most $\alpha$-herpesviruses occurs in epithelial cells of the upper respiratory tract. Sensory neurons of the trigeminal ganglion (TG) that innervate these epithelial cells are predominant target cells for HSV-1, PRV, and BoHV-1 (Gutekunst et al., 1980; Ackermann et al., 1982; Croen et al., 1987).

Correspondence to Herman W. Favoreel: Herman.Favoreel@UGent.be

Abbreviations used in this paper: BoHV, bovine herpesvirus; ERK, extracellular signal-regulated kinase; gD, glycoprotein D; HSV, herpes simplex virus; PFU, plaque-forming unit; PRV, pseudorabies virus; TG, trigeminal ganglion; WT, wild-type. that varicosities serve as axonal exit sites for the virus. Viral envelope glycoprotein $D(g D)$ was found to be necessary and sufficient for the induction of varicosities. Inhibition of Cdc42 Rho GTPase and p38 mitogen-activated protein kinase signaling pathways strongly suppressed gD-induced varicosity formation. These data represent a novel aspect of the cell biology of $\alpha$-herpesvirus infections of sensory neurons, demonstrating that virus attachment/entry is associated with signaling events and neuronal changes that may prepare efficient egress of progeny virus.

Entrance of HSV and PRV in the axons of these sensory neurons is thought to be initiated by an interaction of the viral envelope glycoprotein D (gD) with its receptor nectin-1, followed by fusion of the viral envelope with the axolemma, which is mediated by viral proteins $\mathrm{gB}, \mathrm{gD}, \mathrm{gH}$, and $\mathrm{gL}$ (Haarr et al., 2001; Mata et al., 2001; Milne et al., 2001; Mettenleiter, 2002; Richart et al., 2003; Spear and Longnecker, 2003). Fusion of the viral envelope with the axolemma is followed by retrograde transport of the capsid and a part of the associated tegument to the cell nucleus by means of microtubule-associated fast axonal transport (Tomishima et al., 2001; Smith et al., 2004; Luxton et al., 2005). After entry of the DNA into the nucleus, either a full replication cycle is initiated, leading to the formation of new virions, or a latent infection is established (Jones, 2003). Newly produced virions, during primary infection or after reactivation, are transported in the anterograde direction along the axon, followed by virus release at the axon terminus (Smith et al., 2001; Tomishima and Enquist, 2001, 2002). Recent data indicate that virus egress in axons may not be limited to the axon terminus but also seems to occur at scattered sites along the axon shaft in a manner that remains not 
fully understood (Tomishima and Enquist, 2002; Ch'ng and Enquist, 2005; Saksena et al., 2006).

Despite the obvious importance of TG neurons as predominant target cells and sites of latency/reactivation events for many $\alpha$-herpesviruses, a detailed study of the interactions between $\alpha$-herpesviruses and this pathogenetically important cell type has been hampered by the lack of easy-to-handle, homologous in vitro systems. We recently established such a homologous in vitro two-chamber system, based on the "Campenot" system, to study the interaction between porcine TG neurons and the porcine $\alpha$-herpesvirus PRV (Campenot, 1977; De Regge et al., 2006). Using this in vitro model, we report that PRV induces, via its $\mathrm{gD}$ envelope protein, the formation of presynaptic boutons (varicosities) along the axon shaft of infected TG neurons. Varicosities are swellings along neuronal axons where synaptic vesicles, mitochondria, and ER accumulate (Pannese, 1994). They are able to form synaptic contacts with contacting nonneuronal cells and other axons (Pannese, 1994), but they also seem to play an important role in nonsynaptic communication in the nervous system by the release of neurotransmitters directly in the extrasynaptic space (Zhu et al., 1986; Vizi et al., 2004). We observed that nonneuronal cells aligning the axon shaft of infected TG neurons were frequently infected, and the first infected nonneuronal cells were almost invariably located in close proximity to the varicosities. This suggests that virus-induced varicosities may serve as axon exit sites for the virus to infect neighboring cells.

\section{Results}

Induction of varicosities along the axons of PRV-infected porcine TG neurons

The two-chamber system to study interactions of PRV with porcine TG neurons is mounted on a coverslip and consists of an inner chamber, in which the neuronal culture (composed of neuronal and nonneuronal cells) is seeded, and an outer chamber, and the two are separated from each other by a virus- and medium-impermeable silicon barrier (De Regge et al., 2006). After 2-3 wk of cultivation of trigeminal neurons in the inner chamber, axonal outgrowth through the silicon barrier into the outer chamber was detected by light microscopy. Addition of $2 \times 10^{6}$ plaque-forming units (PFUs) of PRV to the outer chamber resulted in exclusive infection of trigeminal neuronal cell bodies in the inner chamber, as described previously (De Regge et al., 2006).

Surprisingly, axons of PRV-infected neurons (24 h after inoculation) showed a massive amount of bouton-like axonal swellings, which were rarely detected on axons of noninfected cell bodies (Fig. 1 A). Double immunofluorescent stainings using a neuronal cell marker (neurofilament) and a marker for synaptic vesicles (synaptophysin; Fig. 1 B) confirmed that the swellings are presynaptic boutons, also called varicosities. Labeling of the PRV-induced varicosities with FM1-43, a fluorescent marker for firing neurons, indicated that the synaptic transmission at the varicosities is intact (Fig. 1 C). Varicosities were formed between 3 and $6 \mathrm{~h}$ after inoculation and were observed in $>70 \%$ of the axons at both early ( $6 \mathrm{~h}$ after inoculation) and late (24 h after inoculation) stages of infection. In mocktreated cultures, only $12 \%$ of the axons showed varicosities (Fig. 1 D).

\section{A PRV strain that lacks the gD envelope protein is unable to induce the formation of varicosities}

Varicosities could be induced by UV-inactivated PRV (Fig. 2 B), indicating that the trigger for varicosity formation occurs early in infection, either during virus attachment or entry, before the

Figure 1. Induction of varicosities along the axons of PRV-infected porcine TG neurons. (A) Confocal images of TG neurons in the inner chamber of mock- or PRV-infected two-chamber models at $24 \mathrm{~h}$ after inoculation, stained for the neuronal marker neurofilament 68 (Texas red) and PRV antigens (FITC). Arrows point to varicosities. Bar, $20 \mu \mathrm{m}$. (B and C) Confocal images of varicosities in the inner chamber of a two-chamber model at $24 \mathrm{~h}$ after inoculation with $2 \times 10^{6} \mathrm{PFUs}$ of WT-PRV and double stained for neurofilament (Texas red) and the synaptic vesicle marker synaptophysin (FITC; B) or labeled with FM1-43 (C). Bars, $5 \mu \mathrm{m}$. (D) Percentage of axons with varicosities in mock-treated or PRV-inoculated two-chamber models (3, 6, and $24 \mathrm{~h}$ after inoculation). Dato shown represent means \pm SEM of triplicate assays. Percentages indicated by the same letter do not significantly differ $(\alpha=0.05)$.

\section{A}
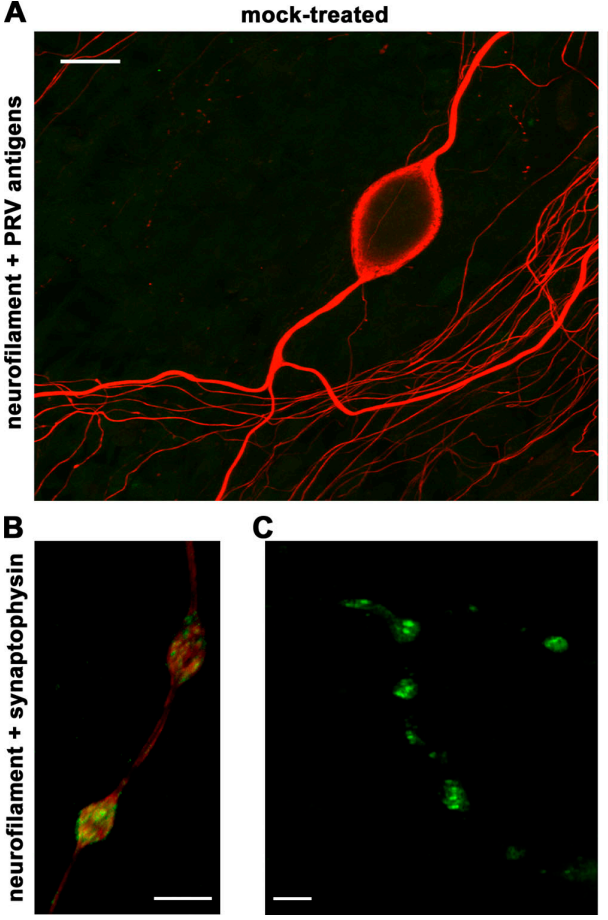

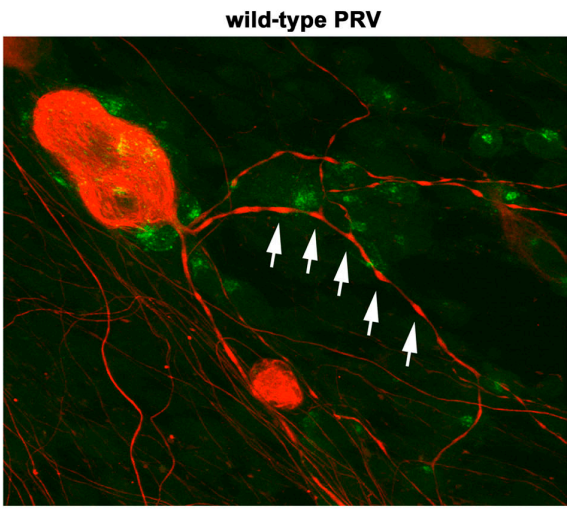

D

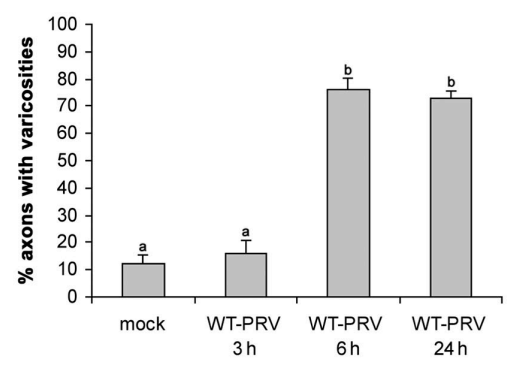


onset of viral protein production. To assess whether induction of varicosities involves the virus entry-essential viral envelope proteins $\mathrm{gB}$ or $\mathrm{gD}$, isogenic stocks of phenotypically and genotypically gBnull- and gDnull-PRV were prepared. Virus stocks were obtained by inoculating phenotypically complemented gBnull- and gDnull-PRV stocks on noncomplementing swine testicle cells and harvesting the progeny virus from the culture supernatant. SDS-PAGE and Western blotting confirmed that $\mathrm{gB}$ and $\mathrm{gD}$ were absent from the gBnull- and gDnull-PRV stocks, respectively (Fig. 2 A). Relative virus particle numbers in the gBnull- and gDnull-PRV stocks were determined as described previously (Qie et al., 1999; Cheshenko and Herold, 2002), by comparing the amount of $\mathrm{gB}$ and $\mathrm{gD}$ in the deleted stocks and in serial dilutions of wild-type (WT)-PRV stock by optical densitometry after Western blotting, as described in Materials and methods.

Virus quantities of gBnull- and gDnull-PRV corresponding to the amount of particles present in $2 \times 10^{6}$ PFUs of WTPRV were added to the outer chamber of the two-chamber system, and the percentages of axons displaying varicosities were determined at $24 \mathrm{~h}$ after inoculation. Varicosity induction by the gBnull virus was comparable to that of WT-PRV (68 vs. $72 \%$, respectively; Fig. 2 B). However, when axons were inoculated with the gDnull virus, the percentage of axons with varicosities was comparable to that of the mock-treated control (14 vs. 12\%, respectively). As expected, neither null virus induced infection of the TG neurons, as neither was able to enter the cells (unpublished data). To exclude the possibility that the lack of synapse induction by the gDnull virus was due to an insufficient amount of virus added, the experiment was repeated
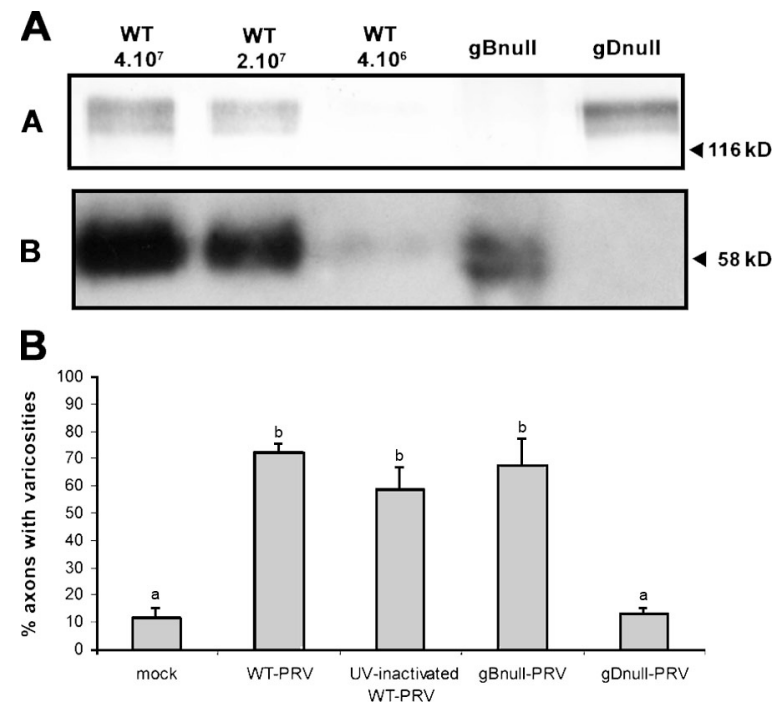

Figure 2. A PRV strain that lacks the $\mathrm{gD}$ envelope protein is unable to induce the formation of varicosities. (A) Western blots of equal volumes of a serial dilution of a WT-PRV stock with known titer (PFU/ml) and gBnull- and gDnull-PRV stocks, developed with anti-gB antibodies (blot $A$ ) or anti-gD antibodies (blot B). (B) Percentage of axons with varicosities $24 \mathrm{~h}$ after inoculation of two-chamber models with an amount of UVinactivated WT-PRV, gBnull-PRV, gDnull-PRV, or WT-PRV particles equivalent to $2 \times 10^{6}$ PFUs of WT-PRV. Data shown represent means \pm SEM of triplicate assays. Percentages indicated by the same letter do not significantly differ $(\alpha=0.05)$. with 10-fold more gDnull virus, and similar results were obtained (unpublished data). In conclusion, a gDnull-PRV strain is unable to induce the formation of varicosities, suggesting that virion $\mathrm{gD}$ triggers this process.

\section{Recombinant PRV-gD protein \\ and nectin-1-specific antibodies \\ induce the formation of varicosities}

To address whether $\mathrm{gD}$ alone could induce varicosities, various concentrations of a truncated, soluble form of PRV-gD (PRV-gDt; Connolly et al., 2001) were added to the outer chamber of the in vitro model and incubated with the axons for $24 \mathrm{~h}$, followed by neurofilament staining and quantification of the number of axons that showed varicosities. Incubation resulted in a dose-dependent increase in the number of axons carrying varicosities (Fig. $3 \mathrm{~A}$ ). The addition of $5 \mu \mathrm{g}$ PRV-gDt $/ \mathrm{ml}$ or more resulted in $60-70 \%$ axons with varicosities (Fig. $3 \mathrm{~A}$ ), which is comparable to the percentages observed by the addition of WT-PRV.

Entry of $\alpha$-herpesviruses, like HSV-1 or PRV, into sensory neurons is believed to be mediated by interaction of viral envelope protein gD with nectin-1 (Haarr et al., 2001; Mata et al., 2001; Milne et al., 2001; Richart et al., 2003). Therefore, we hypothesized that $\mathrm{gD}$-mediated induction of varicosities results from an interaction with nectin-1. To test this hypothesis, we determined whether addition of various concentrations of an antibody that binds the ectodomain of nectin-1 (CK6; Krummenacher et al., 2000) was also able to trigger varicosity formation. As with soluble $\mathrm{gD}$, a 24-h incubation period with monoclonal antinectin-1 antibody in the outer chamber again resulted in a clear dose-dependent response. For antibody CK6, $100 \mu \mathrm{g} / \mathrm{ml}$ caused

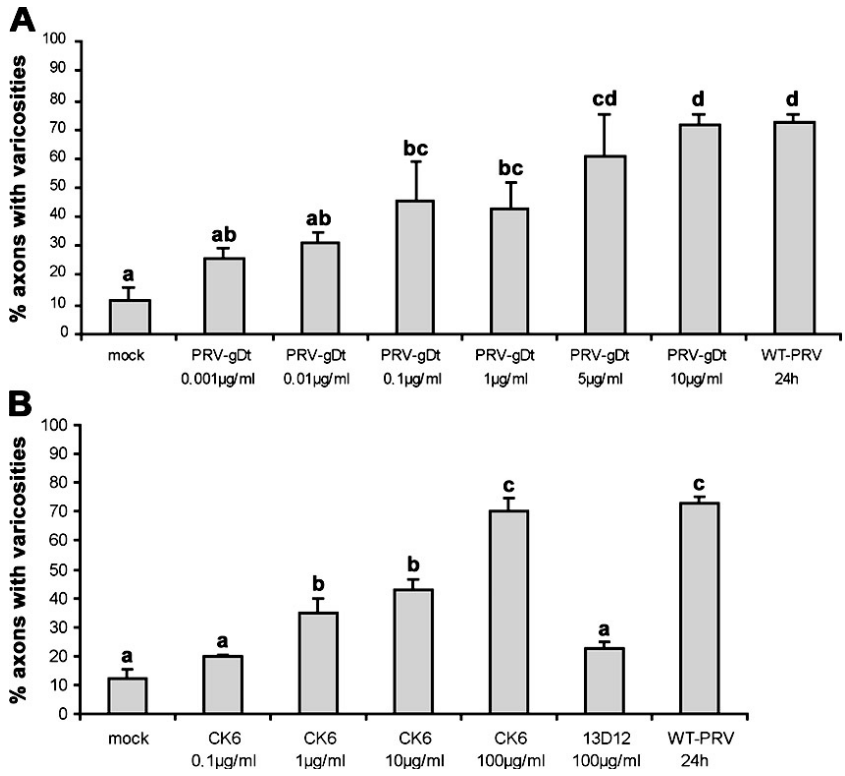

Figure 3. Recombinant $\mathrm{gD}$ protein and nectin-1-specific antibodies induce formation of varicosities in TG neurons. Percentage of axons with varicosities in mock-treated two-chamber models or at $24 \mathrm{~h}$ after addition of recombinant soluble PRV-gD $(0.001-10 \mu \mathrm{g} / \mathrm{ml}$; A), a nectin-1-specific antibody $(0.1-100 \mu \mathrm{g} / \mathrm{ml} \mathrm{CK6})$ or an isotype-matched control antibody $(100 \mu \mathrm{g} / \mathrm{ml} \mathrm{13D12;B}$ ) to the outer chamber of two-chamber systems. Data shown represent means \pm SEM of triplicate assays. Percentages indicated by the same letter do not significantly differ $(\alpha=0.05)$. 
varicosities to form on $70 \%$ of the axons (Fig. 3 B), again similar to the percentage observed by addition of WT-PRV. The addition of $100 \mu \mathrm{g} / \mathrm{ml}$ of CK41, a monoclonal antibody directed against another epitope on the ectodomain of nectin-1, also resulted in induction of varicosity formation (unpublished data). The addition of $100 \mu \mathrm{g} / \mathrm{ml}$ of an isotype-matched control IgG1 antibody (13D12) did not result in an increase in the percentage of axons with varicosities compared with mock-treated two-chamber systems. In conclusion, addition of recombinant $\mathrm{gD}$ or antinectin-1 antibodies to the axons of TG neurons is sufficient to induce the formation of varicosities.

\section{Cdc42 Rho GTPase and p38 MAPK signaling pathways are involved in $\alpha$-herpesvirus-induced varicosity formation} Nectin-1 has been shown to signal via small Rho GTPase signaling pathways in MDCK and L cells (Fukuhara et al., 2003, 2004). In addition, Cdc 42 Rho GTPase and MAPK signaling pathways have been suggested to be involved in varicosity formation (Hu et al., 2004; Nakata et al., 2005; Udo et al., 2006). Therefore, to determine which signaling pathways may be involved in PRV-induced varicosity formation, the effect of inhibitors of different signaling pathways (Rho GTPase and MAPK signaling pathways) were tested for their effect on PRV-induced varicosity formation. A broad-range inhibitor of small Rho GTPase signaling ( $50 \mathrm{ng} / \mathrm{ml}$ Clostridium difficile toxin B) as well as specific inhibitors of Rho (30 $\mu \mathrm{M}$ Y27632), Rac1 (100 $\mu \mathrm{M}$ Rac1 inhibitor), or Cdc42 ( $2 \mu \mathrm{M}$ secramine A) signaling were used. The role of MAPK signaling was examined by using inhibitors for extracellular signal-regulated kinase (ERK) signaling (10 $\mu \mathrm{M}$ U0126), JNK signaling (20 $\mu \mathrm{M}$ JNK inhibitor II), and p38 signaling (20 $\mu \mathrm{M}$ SB203580). General inhibition of small Rho GTPase signaling as well as specific inhibition of Cdc42 signaling suppressed varicosity formation to a level that was not significantly different from mock-infected cultures, whereas specific inhibition of Rho or Rac1 signaling had no obvious effect (Fig. 4 A). Inhibition of p38 MAPK signaling also resulted in a strong reduction of varicosity formation, in contrast to inhibition of ERK or JNK MAPK signaling (Fig. 4 B). These data suggest that PRV activates varicosity formation via signaling pathways dependent on Rho GTPase (in particular Cdc42) and MAPK (in particular p38).

\section{PRV-gD-induced varicosities serve as axonal exit sites for PRV}

The inner chamber of the TG cultures does not consist solely of TG neurons but also contains many nonneuronal cells, which form a monolayer in the inner chamber, in which the TG neurons are dispersed. When the inner chamber of TG neuronal cultures was stained for PRV antigens at $24 \mathrm{~h}$ (or later) after inoculation with WT-PRV in the outer chamber, viral antigenpositive nonneuronal cells were observed aligning the axons of PRV-infected TG neurons. Interestingly, single-infected nonneuronal cells were almost invariably $(88 \%)$ juxtaposed to varicosities (Fig. 5). Spread of PRV from varicosities to neighboring nonneuronal cells could not be blocked by neutralizing antibodies (unpublished data), indicating that it occurs via direct

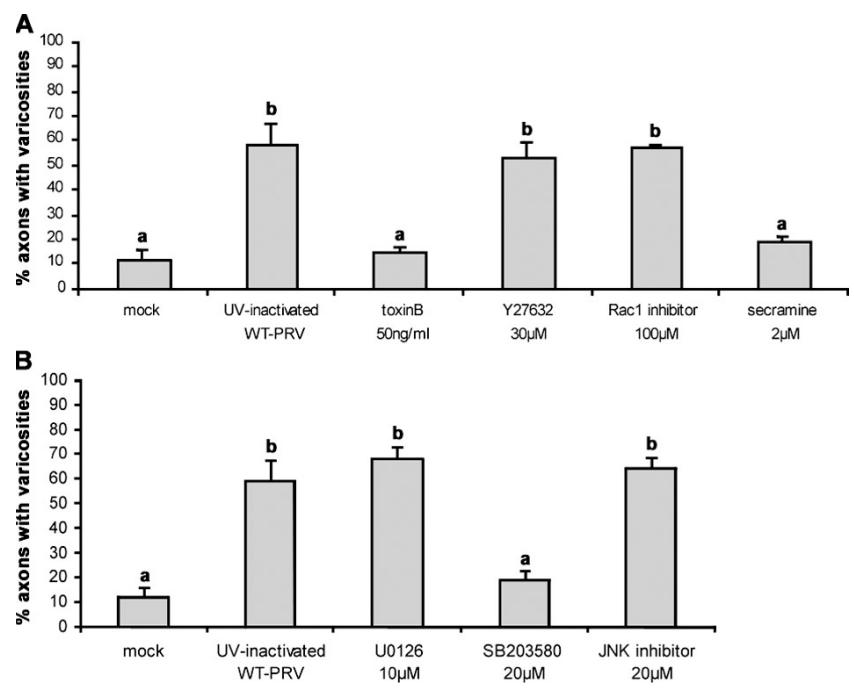

Figure 4. Cdc42 Rho GTPase and p38 MAPK signaling pathways are involved in $\alpha$-herpesvirus-induced varicosity formation. Percentage of axons with varicosities in mock-treated two-chamber models or at $16 \mathrm{~h}$ after incubation with an amount of UV-inactivated PRV particles equivalent to $2 \times 10^{6}$ PFUs of WT-PRV, in the presence of inhibitors directed against (A) small Rho GTPases (C. difficile toxin B), Rho (Y27632), Racl (Racl inhibitor), or Cdc42 (secramine A) or (B) ERK (U0126), JNK (JNK inhibitor II), or p38 MAPK signaling (SB203580). Data shown represent means \pm SEM of triplicate assays. Percentages indicated by the same letter do not significantly differ $(\alpha=0.05)$.

cell-cell spread. These data indicate that egress of infectious virus along the axon shaft occurs specifically at varicosities.

\section{Discussion}

The neurotropic behavior of $\alpha$-herpesviruses is of crucial importance for the pathogenicity of these viruses, allowing them to establish lifelong latency and cause central nervous disorders, encephalitis, and recurrent disease. Neurons of the TG represent crucial target neurons for many $\alpha$-herpesviruses, including HSV-1, PRV, and BoHV-1. The exact cell biology underlying the interactions of $\alpha$-herpesviruses with neurons, especially TG neurons, remains far from fully understood. Here, we used an in vitro model to study the interaction of an $\alpha$-herpesvirus (PRV) with TG neurons of its corresponding host (the pig). We report a novel aspect of the cell biology of $\alpha$-herpesvirus interaction with TG neurons. We found that the interaction of PRV with axons of porcine TG neurons triggers the formation of synaptic boutons (varicosities) along the axons of these neurons. To our knowledge, this is the first paper reporting that a virus infection stimulates the formation of varicosities. In addition, we show that the viral envelope protein $\mathrm{gD}$ is responsible for the induction of varicosities, probably via an interaction with the entry receptor nectin-1 or nectin-like molecules; that Cdc42 Rho GTPase and p38 MAPK signaling pathways are involved; and that virus egress along the axon shaft of infected TG neurons occurs frequently and specifically at these varicosities. These observations open the intriguing possibility that the virus has evolved a strategy to facilitate spread of progeny virus from TG neurons by inducing varicosities at the time of virus attachment and entry in axons. 
A
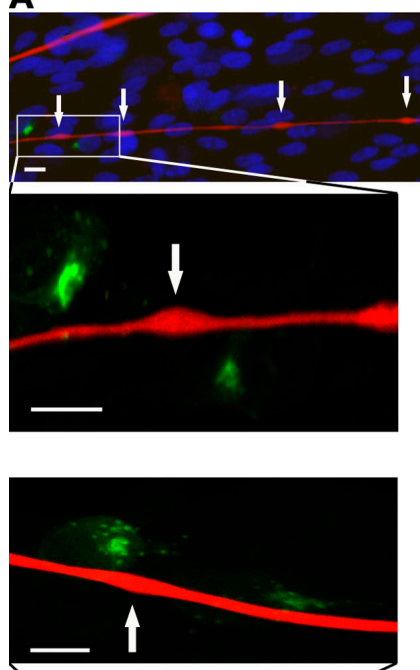

Figure 5. Varicosities serve as axonal exit sites for PRV. (A) Confocal images of TG neuronal cultures in the inner chamber of PRVinfected two-chamber systems at $24 \mathrm{~h}$ after inoculation and stained for neurofilament 68 (Texas red), PRV antigens (FITC), and nuclei (Hoechst 33342). Arrows point to varicosities. Bars, $5 \mu \mathrm{m}$. (B) Graph shows the percentage of single-infected cells that are juxtaposed to varicosities, calculated compared with the total number of single-infected cells. Data shown represent means \pm SEM of four assays.

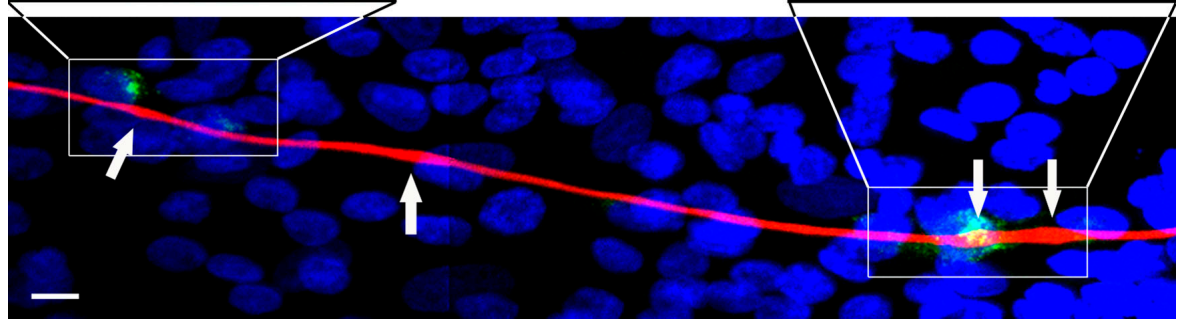

An important question is how exactly PRV induces the formation of varicosities in porcine TG neurons. We found that addition of UV-inactivated PRV (which is able to adhere to and penetrate cells but does not start up viral gene expression) or a strain of PRV that lacks the envelope protein $\mathrm{gB}$ (which is able to adhere to but not penetrate cells) to the axons of TG neurons still resulted in varicosity formation. This shows that varicosity formation is triggered during virus attachment to the axons and does not require infection. Interestingly, a PRV strain that lacks $\mathrm{gD}$ in its envelope (which is also able to adhere to but not penetrate cells) did not induce varicosities, demonstrating an involvement of $\mathrm{gD}$ in this process. Moreover, addition of recombinant soluble gD to the axons of TG neurons was sufficient to trigger varicosity formation. Together, these data indicate that interaction of PRV envelope protein $\mathrm{gD}$ with axons of TG neurons during virus attachment provides the trigger necessary for subsequent formation of varicosities.

How does the interaction of $\mathrm{gD}$ with the surface of axons lead to varicosity formation? Three classes of receptors for $\alpha$-herpesvirus gD proteins have been described to date: one belongs to the tumor necrosis factor receptor family (i.e., herpes virus entry mediator), another class belongs to the immunoglobulin superfamily (including nectin-1 and -2), and another type of receptor consists of modified heparan sulfate (Montgomery et al., 1996; Cocchi et al., 1998; Geraghty et al., 1998; Warner et al., 1998; Shukla et al., 1999; Spear and Longnecker, 2003). Nectin-1 has been suggested to serve as the gD receptor onsensory neurons (like TG neurons) for both HSV and PRV (Haarr et al., 2001; Mata et al., 2001; Milne et al., 2001; Richart et al., 2003). Nectins are cell adhesion molecules that play important roles in the formation of many types of cell-cell junctions, including synapses (Takai et al., 2003). We found that, for both of two different nectin-1-specific antibodies, addition to the axons of TG neurons (as a surrogate ligand for nectin-1 instead of $\mathrm{gD}$ ) resulted in the formation of varicosities. This suggests that the interaction between $\mathrm{gD}$ and nectin- 1 on the axons of TG neurons provides the trigger that ultimately culminates in the formation of varicosities. This would be consistent with observations made by Mizoguchi et al. (2002), who showed that stimulation of nectin-1 in mouse hippocampus neurons resulted in a substantial increase in the number of synaptophysin-positive varicosities. However, at present, we cannot rule out the possibility that other nectins or nectin-like molecules, in addition to or instead of nectin-1 might be relevant to the gD-mediated induction of varicosities. Porcine nectin-1 is thus far the only porcine entry receptor that has been reported for PRV (Milne et al., 2001), but different human forms of the nectin family, like nectin-1, nectin-2, and necl-5 (poliovirus receptor), have been reported to be $\mathrm{gD}$-binding entry receptors for PRV (Geraghty et al., 1998, Connolly et al., 2001).

In addition to a crucial role of the interaction between $\mathrm{gD}$ and nectin-1 and/or other members of the nectin family for the PRV-induced formation of varicosities, we also found that Cdc42 Rho GTPase as well as p38 MAPK signaling pathways are involved. Inhibition of these signaling pathways strongly suppressed PRV-induced varicosity formation. These data are consistent with recent indications that the Cdc42 (but not Rho or Rac) signaling pathway is involved in serotonin-induced varicosity formation in sensory neurons (Udo et al., 2006) and that MAPK signaling pathways, such as p38, may play important roles during development of varicosities (Hu et al., 2004; Nakata et al., 2005). Further in line with our current observations, it has 
been reported that nectin-1 may signal through Rho GTPase pathways, such as Cdc42 and Rac, in MDCK and L cells (Fukuhara et al., 2003, 2004). Our current findings that an $\alpha$-herpesvirus, via its envelope $\mathrm{gD}$, stimulates formation of synaptophysin-positive varicosities and that this process involves Cdc42 and p38 MAPK signaling may, therefore, constitute a valuable tool to further dissect the underlying molecular mechanisms of varicosity formation and the role of nectin-1 and other nectin-like molecules herein.

$\alpha$-Herpesviruses have evolved different strategies to modulate the host cell to facilitate virus spread, such as gE-mediated targeting of virus particles to cell junctions for spread in polarized cells (Collins and Johnson, 2003; Wisner and Johnson, 2004) and intercellular virus spread via US3-induced actin rearrangements and cell projections (Favoreel et al., 2005). Although future in vivo experiments will be required to fully delineate the consequences of our current findings for $\alpha$-herpesvirus pathogenesis, we propose that induction of axonal varicosities by PRV early in infection of TG neurons may be part of the viral strategy to later promote efficient spread.

Varicosity-mediated spread may lead to egress of $\alpha$-herpesviruses along the axon shaft but may also enhance spread of the virus to mucosal surfaces, a crucial step in $\alpha$-herpesvirus pathogenesis. Trigeminal sensory nerve fibers may extend beyond the basement membrane to nearly reach the epithelial surface (Finger et al., 1990). These intraepithelial terminal regions of the axon have penetrated the basement membrane and lost their myelin sheath and are prone to varicosity formation. Strings of varicosities have been reported to occur in these intraepithelial terminal areas of the TG axons in vivo (Kondo et al., 1992, Ibuki et al., 1996).

The exact function of $\alpha$-herpesvirus egress along the entire length of axon shafts is not understood, but PRV egress along axons shafts has clearly been demonstrated in vivo in rats and was found to occur via direct cell-cell spread, which is in line with our current findings (Tomishima and Enquist, 2002). Interestingly, this axonal egress in vivo as well as in vitro was found to occur at scattered sites (Tomishima and Enquist, 2002; Ch'ng and Enquist, 2005). Given our current finding that axonal egress almost exclusively occurs at varicosities, we hypothesize that these scattered sites may correspond to varicosities. In further support of this, a recent paper suggests that axonal egress of HSV-1 occurs via varicosities in human fetal dorsal root ganglia neurons in vitro (Saksena et al., 2006). Transport of progeny herpesvirus particles in the axon is believed to either occur via secretory vesicles containing fully matured virions or as subvirion particles, where capsids and envelope proteins are transported separately and only assemble into mature virions at synapses (Tomishima and Enquist, 2002). In our opinion, both scenarios can lead to specific axonal egress at varicosities, as these structures have been shown to accumulate secretory vesicles and may also constitute functional synapses (Santos et al., 2001).

Virus-induced varicosities endured for at least several days ( $>72 \mathrm{~h}$; unpublished data). It remains to be determined whether and when they disappear after the initial infection. Although speculative at this time, it is possible that the virus is able to reinduce varicosities over and over again when needed during latency/reactivation cycles. Reactivations can lead to production and release of infectious virus, which in turn may attach to and enter new TG neurons, thereby inducing varicosity formation and further promoting virus spread.

It is possible that virus-induced formation of varicosities has consequences beyond virus spread. At least a subpopulation of synaptophysin-positive varicosities function as sites for neurotransmitter release along the axon of different types of neurons (Kohara et al., 2001; Pennuto et al., 2002; Morgenthaler et al., 2003). In line with this, we found that the virus-induced varicosities stain positive for FM1-43, characteristic of intact synaptic transmission. Synaptic transmission was also intact in varicosities induced by $\mathrm{UV}$-inactivated $\mathrm{PRV}$ or recombinant $\mathrm{gD}$ of PRV (unpublished data). In this context, it is interesting to note that $\alpha$-herpesvirus infections have been associated with hyperexcitability of neurons, possibly involved in acquired epilepsy after HSV encephalitis (Chen et al., 2004). Future investigations will be designed to further unravel whether the PRV-induced formation of synaptically effective varicosities lead to changes in excitability of neurons.

In conclusion, we have found that entry of an $\alpha$-herpesvirus in neurons of the TG of its natural host is associated with the induction of synaptic varicosities along the axons. Virus-induced varicosity induction depends on viral envelope protein $\mathrm{gD}$ and on Cdc42 Rho GTPase and p38 MAPK signaling pathways, and the virus uses the varicosities as axonal egress sites to spread to neighboring cells.

\section{Materials and methods}

\section{Viruses and cells}

WT-PRV strain Becker, WT-PRV strain Kaplan, and isogenic deletion mutants gBnull and gDnull were used (Kaplan and Vatter, 1959; Card et al., 1990; Rauh and Mettenleiter, 1991; Rauh et al., 1991). Stocks of phenotypically complemented gBnull and gDnull viruses were grown on gB- and gDcomplementing cell lines. Stocks of phenotypically and genotypically gBnull and gDnull viruses were produced by a single round of infection of phenotypically complemented gBnull and gDnull viruses on noncomplementing swine testicle cells and harvesting the progeny virus from the supernatant.

\section{Antibodies, proteins, and inhibitors}

Monoclonal mouse anti-gB (1C11) and anti-gD (13D12) antibodies and polyclonal porcine FITC-labeled anti-PRV antibodies were produced as previously described (Nauwynck and Pensaert, 1995). The monoclonal neuronal markers mouse anti-neurofilament 68 and rabbit anti-neurofilament 200 and the monoclonal synapse marker mouse anti-synaptophysin were purchased from Sigma-Aldrich. FITC- and Texas red-labeled goat anti-mouse antibodies and Texas red-labeled goat anti-rabbit antibodies were obtained from Invitrogen. Biotinylated sheep anti-mouse $\lg G$ and a streptavidin-biotinylated horseradish peroxidase complex were purchased from GE Healthcare. Inhibitors C. difficile toxin B, Y27632, Rac 1 inhibitor (NSC23766), U0126, SB203580, and JNK inhibitor II were obtained from Calbiochem. Secramine A was used as a specific inhibitor for Cdc42, as described previously (Pelish et al., 2006). PRV-gDt (Connolly et al., 2001) and two monoclonal mouse anti-human antibodies directed against different epitopes on the ectodomain of nectin-1 (CK6 and CK41; Krummenacher et al., 2000) were used.

\section{Quantification of gBnull- and gDnull-PRV stocks}

The number of virus particles in the gBnull and gDnull stock was estimated by optical densitometry, as described previously (Qie et al., 1999; Cheshenko and Herold, 2002). Equal volumes of a serial dilution of a WTPRV stock with a known titer and of stocks of the genotypically and phenotypically gBnull- and gDnull-PRV strains were subjected to SDS-PAGE under nonreducing conditions and Western blotting, followed by detection of $\mathrm{gB}$ or gD using monoclonal gB- and gD-specific antibodies, biotinylated 
secondary sheep anti-mouse antibodies, streptavidin-biotinylated horseradish peroxidase complex, and 3,3'-diaminobenzidine (Sigma-Aldrich) for $\mathrm{gB}$ or enhanced chemiluminescence $(\mathrm{ECL}$ Western blotting analysis system; GE Healthcare) for gD. All antibodies were diluted in PBS with $0.1 \%$ Tween-20 (Sigma-Aldrich), and blots were washed three times in PBS with $0.1 \%$ Tween-20 in between different antibody incubations and after the final antibody incubation. Relative amounts of $\mathrm{gB}$ and $\mathrm{gD}$ in the gDnull and $\mathrm{gBnull}$ stock, respectively, were compared with the amount of $\mathrm{gB}$ and gD present in the WT stocks using Quantity One 1-D analysis software (Bio-Rad Laboratories).

\section{Immunofluorescence staining procedures}

After being washed in PBS, neuronal cultures in the inner and outer chamber of the two-chamber model were fixed in 100\% methanol for $20 \mathrm{~min}$ at $-20^{\circ} \mathrm{C}$, except for cultures that were labeled for synaptophysin, which were fixed using $4 \%$ paraformaldehyde in PBS for $10 \mathrm{~min}$ and subsequently permeabilized in $0.2 \%$ Triton X-100 (Sigma-Aldrich) in PBS for $2 \mathrm{~min}$. All antibodies were diluted in PBS to 1:100. Cells were incubated with each antibody for $1 \mathrm{~h}$ at $37^{\circ} \mathrm{C}$ and were washed two times in PBS in between all incubation steps and after the last incubation step. When necessary, nuclei were stained using $10 \mu \mathrm{g} / \mathrm{ml}$ Hoechst 33342 (Invitrogen) for $10 \mathrm{~min}$ before the final washing steps.

\section{Cultivation, inoculation, and analysis of primary TG neuronal cultures in a two-chamber model}

Porcine TG neurons were obtained as described previously (Geenen et al., 2005) and seeded in an in vitro model based on the "Campenot" system (Campenot, 1977), which allows simulation of the in vivo route of neuronal infection (De Regge et al., 2006). In brief, porcine TG were excised from 4-6-wk-old piglets and dissociated by enzymatic digestion with $0.2 \%$ collagenase A (Roche). The harvested cells were resuspended in culture medium (basic culture medium without glutamine) and supplemented with $30 \mathrm{ng} / \mathrm{ml}$ nerve growth factor (Sigma-Aldrich) and seeded in the inner chamber of an in vitro two-chamber model. The two-chamber system consists of a polyallomer tube that is fixed with silicon grease on a collagencoated cover glass inserted in a 6-well plate (Nunc). The inside of the tube forms the inner chamber, and the outside forms the outer chamber. The silicon barrier prevents diffusion of medium or virus from one chamber to the other (De Regge et al., 2006). 1 d after seeding, cultures were washed with RPMI (Invitrogen) to remove nonadherent cells and, from then on, culture medium was changed three times a week.

After 2-3 wk of cultivation, when clear axon growth could be observed in the outer chamber, the outer chamber was inoculated with $2 \times 10^{6}$ PFUs of WT-PRV or with an equivalent number of UV-inactivated, gBnull- or gDnull-PRV particles. In some experiments, the outer chamber was incubated with soluble PRV-gD (ranging from 0.001 to $10 \mu \mathrm{g} / \mathrm{ml}$ ), with antibodies directed against nectin-1 (CK6, ranging from 0.1 to $100 \mu \mathrm{g} / \mathrm{ml}$, or CK41, $100 \mu \mathrm{g} / \mathrm{ml})$ or with an isotype-matched (lgG1) control antibody directed to the viral envelope $\mathrm{gD}(100 \mu \mathrm{g} / \mathrm{ml} 13 \mathrm{D} 12$; Nauwynck and Pensaert, 1995; Krummenacher et al., 2000).

The percentage of axons showing varicosities after different treatments was determined by fluorescent labeling using anti-neurofilament antibodies and examination of 30 axons with outgrowth in the outer chamber of different two-chamber models for the presence of multiple $>5 / 250 \mu \mathrm{m}$ axon) swellings that were at least 1.5 times the diameter of the axon. Data shown represent means \pm SEM of triplicate assays.

\section{FM1-43-labeling procedure}

The firing capacity of the induced varicosities was determined by loading the neurons with FM1-43 (Invitrogen), basically as described before (Mizoguchi et al., 2002). After 2-3 wk in culture, the outer chamber was treated for $24 \mathrm{~h}$ with $2 \times 10^{6} \mathrm{PFUs}$ of WT-PRV, an equivalent number of UV-inactivated PRV particles, or $10 \mu \mathrm{g} / \mathrm{ml}$ soluble PRV-gD. Then, the inner chamber was washed with Hanks' balanced salt solution supplemented with $100 \mathrm{mM} \mathrm{KCl}$ and $1.5 \mathrm{mM} \mathrm{CaCl}_{2}$ for $1 \mathrm{~min}$. The neurons were incubated with culture medium containing $100 \mathrm{mM} \mathrm{KCl}$ and $20 \mu \mathrm{M} \mathrm{FMl-43}$ for $10 \mathrm{~min}$. After being washed with Hanks' balanced salt solution for $15 \mathrm{~min}$, cultures were mounted on coverslips without fixation and examined by confocal microscopy.

\section{Inhibitor studies}

To examine the effect of different inhibitors on varicosity formation, both the inner and outer chamber of the two-chamber system were pretreated with culture medium supplemented with the respective inhibitor for $2 \mathrm{~h}$. Afterward, the outer chamber was incubated with UV-inactivated PRV particles equivalent to $2 \times 10^{6} \mathrm{PFUs}$ of WT-PRV in the presence of the inhibitor. After an incubation period of $16 \mathrm{~h}$, the two-chamber system was methanol fixed and stained, and the percentage of axons showing varicosities was determined as described (see Cultivation, inoculation, and analysis...).

\section{Quantification of single-infected cells juxtaposed to varicosities}

Single-infected cells were scored as juxtaposed to a varicosity when the signal of the viral antigens (FITC signal) contacted the varicosity (Texas red signal), as seen in two-chamber models fixed at $24 \mathrm{~h}$ after inoculation with $2 \times 10^{6}$ PFUs of WT-PRV and stained with polyclonal FITC-labeled anti-PRV antibodies and the neuronal cell marker anti-neurofilament 68 (Texas red). 50 single-infected cells were analyzed, and data shown represent the mean \pm SEM of four assays

\section{Confocal microscopy}

Stainings were analyzed on a laser-scanning spectrum confocal system (TCS SP2; Leica Microsystems GmbH) linked to a microscope (DM IRBE; Leica Microsystems $\mathrm{GmbH}$ ). Images were taken using a $63 \times$ oil objective (NA 1.40-0.60) at room temperature and using confocal acquisition software (Leica Microsystems $\mathrm{GmbH}$ ). Adjustments of brightness and contrast were applied to the entire images and were done using Photoshop (Adobe).

\section{Statistics}

The mean percentages of axons displaying varicosities after the different treatments were compared with an analysis of variance and a least significant difference post hoc test for a multiple comparison of means $(\alpha=0.05)$.

The authors would like to thank Carine Boonen, Lieve Sys, Chantal Vanmaerke, and Nele Dennequin for excellent technical assistance and Kevin Braeckmans for help with confocal microscopy. We also would like to thank the Kirchhausen laboratory (Harvard Medical School) and the Hammond laboratory (University of Lovisville) for the kind gift of secramine A that was synthesized by B. Xu and G.B. Hammond of the University of Louisville.

This research was supported by a concerted research action of the research council of Ghent University and research grant G.0227.04 from the Research Foundation-Flanders (FWO-Vlaanderen). N. De Regge is the recipient of a grant from the Institute for the Promotion of Innovation Through Science and Technology in Flanders (IWT-Vlaanderen). C. Krummenacher is supported by an award from the University of Pennsylvania Research Foundation. This investigation was supported in part by Public Health Service grant NS-36731 from the National Institute of Neurological Disease and Stroke (to R.J. Eisenberg and G.H. Cohen) and grants Al-056045 and Al-1 8289 from the National Institute of Allergy and Infectious Diseases (to R.J. Eisenberg and G.H. Cohen, respectively).

Submitted: 28 October 2005

Accepted: 14 June 2006

\section{References}

Ackermann, M., E. Peterhans, and R. Wyler. 1982. DNA of bovine herpesvirus type 1 in the trigeminal ganglia of latently infected calves. Am. J. Vet. Res. 43:36-40.

Campenot, R.B. 1977. Local control of neurite development by nerve growth factor. Proc. Natl. Acad. Sci. USA. 74:4516-4519.

Card, J.P., L. Rinaman, J.S. Schwaber, R.R. Miselis, M.E. Whealy, A.K. Robbins, and L.W. Enquist. 1990. Neurotropic properties of pseudorabies virus: uptake and transneuronal passage in the rat central nervous system. J. Neurosci. 10:1974-1994.

Chen, S.F., C.C. Huang, H.M. Wu, S.H. Chen, Y.C. Liang, and K.S. Hsu. 2004. Seizure, neuron loss, and mossy fiber sprouting in herpes simplex virus type-1 infected organotypic hippocampal cultures. Epilepsia. 45:322-332.

Cheshenko, N., and B.C. Herold. 2002. Glycoprotein B plays a predominant role in mediating herpes simplex virus type 2 attachment and is required for entry and cell-to-cell spread. J. Gen. Virol. 83:2247-2255.

Ch'ng, T.H., and L.W. Enquist. 2005. Neuron-to-cell spread of pseudorabies virus in a compartmented neuronal culture system. J. Virol. 79:10875-10889.

Cocchi, F., L. Menotti, P. Mirandola, M. Lopez, and G. Campadelli-Fiume. 1998. The ectodomain of a novel member of the immunoglobulin subfamily related to the poliovirus receptor has the attributes of a bona fide receptor for herpes simplex virus types 1 and 2 in human cells. J. Virol. 72:9992-10002.

Collins, W.J., and D.C. Johnson. 2003. Herpes simplex virus gE/gI expressed in epithelial cells interferes with cell-to-cell spread. J. Virol. 77:2686-2695. 
Connolly, S.A., J.C. Whitbeck, A.H. Rux, C. Krummenacher, S. van Drunen Littel-van den Hurk, G.H. Cohen, and R.J. Eisenberg. 2001. Glycoprotein $\mathrm{D}$ homologs in herpes simplex virus type 1, pseudorabies virus, and bovine herpes virus type 1 bind directly to human HveC (nectin-1) with different affinities. Virology. 280:7-18.

Croen, K.D., J.M. Ostrove, L.J. Dragovic, J.E. Smialek, and S.E. Straus. 1987. Latent herpes simplex virus in human trigeminal ganglia: detection of an immediate early gene "antisense" transcript by in situ hybridisation. N. Engl. J. Med. 317:1427-1432.

De Regge, N., H.W. Favoreel, K. Geenen, and H.J. Nauwynck. 2006. A homologous in vitro model to study interactions between alphaherpesviruses and trigeminal ganglion neurons. Vet. Microbiol. 113:251-255.

Enquist, L.W., M.J. Tomishima, S. Gross, and G.A. Smith. 2002. Directional spread of an $\alpha$-herpesvirus in the nervous system. Vet. Microbiol. 86:5-16.

Favoreel, H.W., G. Van Minnebruggen, D. Adriaensen, and H.J. Nauwynck. 2005. Cytoskeletal rearrangements and cell extensions induced by the US3 kinase of an alphaherpesvirus are associated with enhanced spread. Proc. Natl. Acad. Sci. USA. 102:8990-8995.

Finger, T.E., V.L. St Jeor, J.C. Kinnamon, and W.L. Silver. 1990. Ultrastructure of substance P- and CGRP-immunoreactive nerve fibers in the nasal epithelium of rodents. J. Comp. Neurol. 294:293-305.

Fukuhara, A., K. Shimizu, T. Kawakatsu, T. Fukuhara, and Y. Takai. 2003. Involvement of nectin-activated $\mathrm{Cdc} 42$ small $\mathrm{G}$ protein in organization of adherens and tight junctions in Madin-Darby canine kidney cells. J. Biol. Chem. 278:51885-51893.

Fukuhara, T., K. Shimizu, T. Kawakatsu, T. Fukuyama, Y. Minami, T. Honda, T. Hoshino, T. Yamada, H. Ogita, M. Okada, and Y. Takai. 2004. Activation of $\mathrm{Cdc} 42$ by trans interactions of the cell adhesion molecules nectins through c-Src and Cdc42-GEF FRG. J. Cell Biol. 166:393-405.

Geenen, K., H.W. Favoreel, and H.J. Nauwynck. 2005. Higher resistance of porcine trigeminal ganglion neurons towards pseudorabies virus-induced cell death compared with other porcine cell types in vitro. J. Gen. Virol. $86: 1251-1260$.

Geraghty, R.J., C. Krummenacher, G.H. Cohen, R.J. Eisenberg, and P.G. Spear. 1998. Entry of alphaherpesviruses mediated by poliovirus receptorrelated protein 1 and poliovirus receptor. Science. 280:1618-1620.

Gutekunst, D.E., E.C. Pirtle, L.D. Miller, and W.C. Steward. 1980. Isolation of pseudorabies virus from trigeminal ganglia of a latently infected sow. Am. J. Vet. Res. 41:1315-1316.

Haarr, L., D. Shukla, E. Rodahl, M.C. Dal Canto, and P.G. Spear. 2001. Transcription from the gene encoding the herpesvirus entry receptor nectin-1 (HveC) in nervous tissue of adult mouse. Virology. 287:301-309.

Hu, J.Y., L. Glickman, F. Wu, and S. Schacher. 2004. Serotonin regulates the secretion and autocrine action of a neuropeptide to activate MAPK required for long-term facilitation in Aplysia. Neuron. 43:373-385.

Ibuki, T., M.A. Kido, T. Kiyoshima, Y. Terada, and T. Tanaka. 1996. An ultrastructural study of the relationship between sensory trigeminal nerves and odontoblasts in rat dentin/pulp as demonstrated by the anterograde transport of wheat germ agglutinin-horseradish peroxidase (WGA-HRP). J. Dent. Res. 75:1963-1970.

Jones, C. 2003. Herpes simplex virus type I and bovine herpesvirus I latency. Clin. Microbiol. Rev. 16:79-95.

Kaplan, A.S., and A.E. Vatter. 1959. A comparison of herpes simplex virus and pseudorabies virus. Virology. 7:394-407.

Kohara, K., A. Ogura, K. Akagawa, and K. Yamaguchi. 2001. Increase in number of functional release sites by cyclic AMP-dependent protein kinase in cultured neurons isolated from hippocampal dentate gyrus. Neurosci. Res. 41:79-88.

Kondo, T., N. Ayasaka, E. Nagata, and T. Tanaka. 1992. A light and electron microscopic anterograde WGA-HRP tracing study on the sensory innervation of junctional and sulcular epithelium in the rat molar. J. Dent. Res. 71:60-65.

Krummenacher, C., I. Baribaud, M. Ponce de Leon, J.C. Whitbeck, H. Lou, G.H. Cohen, and R.J. Eisenberg. 2000. Localization of a binding site for herpes simplex virus glycoprotein D on herpesvirus entry mediator $\mathrm{C}$ by using antireceptor monoclonal antibodies. J. Virol. 74:10863-10872.

Luxton, G.W., S. Haverlock, K.E. Coller, S.E. Antinone, A. Pincetic, and G.A. Smith. 2005. Targeting of herpesvirus capsid transport in axons is coupled to association with specific sets of tegument proteins. Proc. Natl. Acad. Sci. USA. 102:5832-5837.

Mata, M., M. Zhang, X. Hu, and D.J. Fink. 2001. HveC (nectin-1) is expressed at high levels in sensory neurons, but not in motor neurons, of the rat peripheral nervous system. J. Neurovirol. 7:476-480.

Mettenleiter, T.C. 2002. Brief overview on cellular virus receptors. Virus Res. 82:3-8.
Milne, R.S.B., S.A. Connolly, C. Krummenacher, R.J. Eisenberg, and G.H Cohen. 2001. Porcine HveC, a member of the highly conserved HveC/ nectin-1 family, is a functional alphaherpesvirus receptor. Virology. 281:315-328.

Mizoguchi, A., H. Nakanishi, K. Kimura, K. Matsubara, K. Ozaki-Kuroda, T. Katata, T. Honda, Y. Kiyohara, K. Heo, M. Higashi, et al. 2002. Nectin: an adhesion molecule involved in formation of synapses. J. Cell Biol. 156:555-565.

Montgomery, R.I., M.S. Warner, B.J. Lum, and P.G. Spear. 1996. Herpes simplex virus- 1 entry into cells mediated by a novel member of the TNF/NGF receptor family. Cell. 87:427-436.

Morgenthaler, F.D., G.W. Knott, J.C. Floyd Sarria, X. Wang, J.K. Staple, S. Catsicas, and H. Hirling. 2003. Morphological and molecular heterogeneity in release sites of single neurons. Eur. J. Neurosci. 7:1365-1374.

Nakata, K., B. Abrams, B. Grill, A. Goncharov, X. Huang, A.D. Chisholm, and Y. Jin. 2005. Regulation of a DLK-1 and p38 MAP kinase pathway by the ubiquitin ligase RPM-1 is required for presynaptic development. Cell. 120:407-420.

Nauwynck, H.J., and M.B. Pensaert. 1995. Effect of specific antibodies on the cell-associated spread of pseudorabies virus in monolayers of different cell types. Arch. Virol. 140:1137-1146.

Pannese, E. 1994. Neurocytology: Fine Structure of Neurons, Nerve Processes and Neuroglial Cells. Thieme Medical Publishers, Inc., New York. 264 pp.

Pelish, H.E., J.R. Peterson, S.B. Salvarezza, E. Rodriguez-Boulan, J.L. Chen, M. Stamnes, E. Macia, Y. Feng, M.D. Shair, and T. Kirchhausen. 2006. Secramine inhibits Cdc42-dependent functions in cells and $\mathrm{Cdc} 42$ activation in vitro. Nat. Chem. Biol. 2:39-46.

Pennuto, M., D. Dunlap, A. Contestabile, F. Benfenati, and F. Valtorta. 2002. Fluorescence resonance energy transfer detection of synaptophysin I and vesicle-associated membrane protein 2 interactions during exocytosis from single live synapses. Mol. Biol. Cell. 13:2706-2717.

Preston, C.M. 2000. Repression of viral transcription during herpes simplex virus latency. J. Gen. Virol. 81:1-19.

Qie, L., D. Marcellino, and B.C. Herold. 1999. Herpes simplex virus entry is associated with tyrosine phosphorylation of cellular proteins. Virology. 256:220-227.

Rauh, I., and T.C. Mettenleiter. 1991. Pseudorabies virus glycoproteins gII and gp50 are essential for virus penetration. J. Virol. 65:5348-5356.

Rauh, I., F. Weiland, F. Fehler, G.M. Keil, and T.C. Mettenleiter. 1991. Pseudorabies virus mutants lacking the essential glycoprotein gII can be complemented by glycoprotein gI of bovine herpesvirus 1. J. Virol. 65:621-631.

Richart, S.M., S.A. Simpson, C. Krummenacher, J.C. Whitbeck, L.I. Pizer, G.H. Cohen, R.J. Eisenberg, and C.L. Wilcox. 2003. Entry of herpes simplex virus type 1 into primary sensory neurons in vitro is mediated by nectin-1/ HveC. J. Virol. 77:3307-3311.

Santos, M.S., J. Barbosa, Jr., G.S. Veloso, F. Ribeiro, C. Kushmerick, M.V. Gomez, S.S.G. Ferguson, V.F. Prado, and M.A.M. Prado. 2001 Trafficking of green fluorescent protein tagged-vesicular acetylcholine transporter to varicosities in a cholinergic cell line. J. Neurochem. 78:1104-1113.

Saksena, M.M., H. Wakisaka, B. Tijono, R.A. Boadle, F. Rixon, H. Takahashi, and A.L. Cunningham. 2006. Herpes simplex virus type 1 accumulation, envelopment, and exit in growth cones and varicosities in mid-distal regions of axons. J. Virol. 80:3592-3606.

Shukla, D., J. Liu, P. Blaiklock, N.W. Shworak, X. Bai, J.D. Esko, G.H. Cohen, R.J. Eisenberg, R.D. Rosenberg, and P.G. Spear. 1999. A novel role for 3-O-sulfated heparan sulfate in herpes simplex virus 1 entry. Cell. 99:13-22.

Smith, G.A., S.P. Gross, and L.W. Enquist. 2001. Herpesviruses use bidirectional fast-axonal transport to spread in sensory neurons. Proc. Natl. Acad. Sci. USA. 98:3466-3470.

Smith, G.A., L. Pomeranz, S.P. Gross, and L.W. Enquist. 2004. Local modulation of plus-end transport targets herpesvirus entry and egress in sensory axons. Proc. Natl. Acad. Sci. USA. 101:16034-16039.

Spear, P.G., and R. Longnecker. 2003. Herpesvirus entry: an update. J. Virol. 77:10179-10185.

Takai, Y., K. Shimizu, and T. Ohtsuka. 2003. The roles of cadherins and nectins in interneuronal synapse formation. Curr. Opin. Neurobiol. 13:520-526.

Tomishima, M.J., and L.W. Enquist. 2001. A conserved $\alpha$-herpesvirus protein necessary for axonal localization of viral membrane proteins. J. Cell Biol. 154:741-752.

Tomishima, M.J., and L.W. Enquist. 2002. In vivo egress of an alphaherpesvirus from axons. J. Virol. 76:8310-8317.

Tomishima, M.J., G.A. Smith, and L.W. Enquist. 2001. Sorting and transport of alpha herpesviruses in axons. Traffic. 2:429-436. 
Udo, H., I. Jin, J.H. Kim, H.L. Li, T. Youn, R.D. Hawkins, E.R. Kandel, and C.H. Bailey. 2005. Serotonin-induced regulation of the actin network for learning-related synaptic growth requires Cdc42, N-WASP, and PAK in Aplysia sensory neurons. Neuron. 45:887-901.

Vizi, E.S., J.P. Kiss, and B. Lendvai. 2004. Nonsynaptic communication in the central nervous system. Neurochem. Int. 45:443-451.

Warner, M.S., R.J. Geraghty, W.M. Martinez, R.I. Montgomery, J.C. Whitbeck, R. Xu, R.J. Eisenberg, G.H. Cohen, and P.G. Spear. 1998. A cell surface protein with herpesvirus entry activity $(\mathrm{HveB})$ confers susceptibility to infection by mutants of herpes simplex virus type 1 , herpes simplex virus type 2, and pseudorabies virus. Virology. 246:179-189.

Wisner, T.W., and D.C. Johnson. 2004. Redistribution of cellular and herpes simplex virus proteins from the trans-Golgi network to cell junctions without enveloped capsids. J. Virol. 78:11519-11535.

Zhu, P.C., A. Thureson-Klein, and R.L. Klein. 1986. Exocytosis from largedense cored vesicles outside the active synaptic zones of terminals within the trigeminal subnucleus caudalis: a possible mechanism for neuropeptide release. Neuroscience. 19:43-54. 